\title{
Mass media discourse deployment and its gender specificity: sociolinguistic perspective
}

\author{
Inna V. Skrynnikova - Tatjana N. Astafurova - Elena S. Aleksandrova
}

\section{DOI: 10.18355/XL.2017.10.03.24}

\begin{abstract}
The current paper deals with the sociolinguistic analysis of mass media discourse deployment and its gender specificity. It reveals sociocultural factors and psychological peculiarities affecting speech generating mental activity of male and female authors of British news texts as representatives of the native English-speaking community. The paper also touches upon the differences in male and female perception of events and their reflection in gender-neutral texts giving rise to feminine and masculine forms of writing. An attempt has been made to classify and describe linguistic parameters of newspaper texts written by male and female authors. The authors pay special attention to the gender analysis of structural, contents and stylistic aspects of news texts. The proposed matrix for identifying gender of a news text author has been validated by the results of the sociolinguistic experiment providing some insights into gender specificity of the mass media texts on various levels of language.
\end{abstract}

Key words: gender studies, discourse deployment, sociolinguistics, information structure, mass-media discourse, news text

\section{Introduction \\ 1.1 Stating the problem}

Recent years have seen a great body of research on gender peculiarities of speech behaviour of linguistic and cultural communities as well as professional and age groups in everyday discourse (Cameron, 1998; Sternin et al.), political discourse (Anthonissen, 2007), advertising discourse (Groshev, 1999) and scientific discourse (Grishaeva 2007 et al.). Considerable attention has been traditionally paid to forming gender stereotypes in the discourse of mass media (Tolson , 2006; Kitaigorodskaya, 2003). However, the discourse deployment particularities of gender-neutral news texts by male and female authors are still a relatively neglected topic. It should be noted that gender is understood here as a complex of social and psychological processes and cultural attitudes affecting an individual's behavior, his/her choice of social and speech strategies. The current paper, being an attempt to fill the gap in the gender studies, claims that gender markedness of news texts is influenced by social and cultural as well as psychological factors of event perception by male and female authors - representatives of a particular linguistic culture - and is revealed at the contents, structural and stylistic levels of analysis.

\subsection{Research background}

Gender studies in the 1970-s - 1990-s were carried out within the four main paradigms of research: the feminine language "deficit" theory, the dominant theory, the trim theory and the performativity theory. The two first lines of research (Fishman, 1983; Lakoff, 1973; Henley, 1977 West, Zimmerman, 1975, 1983) emphasize "dominant masculinity" as a basic concept where women are considered to be a discriminated social group, and linguistic differences are interpreted in terms of "powerful masculine language" and "powerless feminine language". The proponents of the trim theory (Maltz, Borker, 1982, Tannen, 1994, Coats, 1999, etc.) explain 
gender differences by the existence of "communicatively opposite subcultures feminine and masculine - originating from early childhood where different cultural worlds (boys' world and girls' world) are created and developed (Tannen, 1994). The performativity theory (Butler, 1990; 1993, Eckert, McConnell-Gine, 1994; 2003) sees gender as a ranging phenomenon influenced by social changes.

Gender research in Russian linguistics, which has been intensely developing since the mid-1990-s, fall into psycholinguistic and sociolinguistic studies, masculine linguistics and linguocultural gender studies. But the question of correlation between biological, psychological, social and cultural factors affecting the gender differences in language and speech was and has been the topic of hot debate and is still open for discussion. The biodeterministic approach points out to the crucial role of differences in hormonal systems and brain asymmetry in men and women affecting their speech behavior. As a result there are cognitive, emotional and physical parameters of gender differentiation. Sociodeterministic theories including feminine and masculine linguistics emphasize the decisive role of society and culture as dynamic and mobile social factors influencing the formation of gender differences. The results of the analysis of men and women's communicative behaviour in the socialization process in different cultures seem to support this claim. Taking into account biological, psychological and social differences of male and female society members, gender studies have revealed that it is not ascertaining of gender differences that is particularly important but rather their social and cultural evaluation and interpretation underlying the system of gender dominance accepted in a society.

\section{Text generating styles}

\subsection{Parameters of text generating styles}

Gender differences in language and speech create gender stereotypes which are determined by men and women's social roles and affect a person's gender selfidentification in accordance with sociocultural settings, norms and rules of a particular society. The concepts of femininity and masculinity serving as the basis of gender stereotypes have undergone dramatic changes reflected in discrepancy of a person's sex and psychological manifestation of gender. The analysis of numerous gender studies has shown that modern women achieving high professional status are generally more masculine than their modern male counterparts who lack "the ban on emotion, greater open-heartedness and doing traditionally women's work» (Zdravomyslova, 2000). Thus, masculinity and femininity are not quite opposite but rather interrelated categories reflecting social processes. As a result the crucial parameters of masculinity (aggressiveness, bossiness, dominance, independence, decisiveness, ambitiousness) as well as femininity (emotionality, solicitude, friendliness, politeness, open-heartedness) have also changed greatly. However, as it follows from our research, despite the blurry distinction between femininity and masculinity, gender markers can still be found in news texts.

The research done in feminine and masculine linguistics (Goroshko, 1995, 1999; Issers, 1999; Sternin, 1999; Lakoff, 1973) has shown that studies of gender specificity in different types of texts from contents, punctuation, orthographic, syntactic, lexical, phraseological, and stylistic perspectives enable to point out the following parameters of masculine and feminine text generating styles:

- thematic (mainly women's topics - family, health, education; mainly men's topics

- politics, science, cars, sport, career);

- communicative-pragmatic (female communicative behavior is characterized by cooperative strategies, indirect and phatic speech acts, empathy, communicative flexibility, delegating authority while male communicative behavior is based on competitive strategies, communication leadership, imperative speech acts, authority and power); 
- syntactic (female syntax is expressed by subordinate connection, exclamatory and interrogative sentences, passive voice, elliptic and inverted constructions while male syntax is based on complex and compound sentences and active voice constructions);

- stylistic ( the basis of female stylistics is hyperbolized expressivity, emphasis on positive evaluation, high percentage of positive emotive vocabulary and diminutive suffixes; male stylistics is characterized by high percentage of professional terminology, stylistically neutral and negative emotion vocabulary, invectives and derogative words).

The parameters of male and female styles of generating texts turn into verbal stereotypes underlying identification of an author's gender. In this respect a news text, whose gender specificity can be marked, is not an exception.

\subsection{Data and experiment}

To validate the parameters of masculine and feminine text generating styles we have conducted a two-stage sociolinguistic experiment. At the first stage of the experiment 40 respondents with no history of language disorders, both native and non-native English speakers (14 native British and American English speakers, aged 29-45, and 26 non-native English speakers from Malaysia, aged 19-25) were asked to identify an author's gender after reading six gender-neutral news texts about the calamities in different parts of the world. Over 100 news texts were selected by random sampling from British quality papers (The Guardian, The Observer, The Times) published between 2005 and 2015.

The results of the first experiment have shown that in the group of native speakers the authors' gender was correctly identified by $84 \%$ of male respondents and $79 \%$ of female respondents, while in the non-native group $75 \%$ of male respondents and only $3 \%$ of female respondents have managed to do so. There is insignificant difference in the response accuracy of male speakers of the two groups. The considerable difference in the response accuracy between female respondents of the native and non-native group might probably be explained by socio- and linguocultural differences of native and non-native English speakers. The USA and Great Britain seeking to become the nations of gender equality and promoting political correctness, have actively studied the problems of gender differences from linguistic and sociocultural perspectives and cover them in national mass media, equally available for men and women. This factor might have contributed to higher accuracy of identifying the gender of authors creating news texts within the group of native English speakers. In contrast, Malaysia is a Muslim country where Asian values are opposed to Western ones, which implies gender discrimination of women in all social spheres, unequal access to information for men and women. It may explain the low "sensitivity" of Malaysian females to gender differences in masculine and feminine styles of text generating. The results of the first experiment are summarized in Table 1 .

Table 1. Accuracy rates of identifying author's gender

\begin{tabular}{|c|c|c|c|c|}
\hline \multirow{2}{*}{$\begin{array}{l}\text { Number of texts } \\
\text { with accurately } \\
\text { identified author's } \\
\text { gender }\end{array}$} & \multicolumn{2}{|c|}{ Native English speakers } & \multicolumn{2}{|c|}{$\begin{array}{l}\text { Non-native } \\
\text { speakers }\end{array}$} \\
\hline & $\begin{array}{l}\text { men } \\
\%\end{array}$ & $\begin{array}{l}\text { women } \\
\%\end{array}$ & $\begin{array}{l}\text { men } \\
\%\end{array}$ & $\begin{array}{l}\text { women } \\
\%\end{array}$ \\
\hline 6 & 42 & 38 & 24 & 2 \\
\hline 4 & 23 & 29 & 18 & 3 \\
\hline 3 & 35 & 33 & 11 & 1 \\
\hline
\end{tabular}

XLinguae Journal, Volume 10 Issue 3, June 2017, ISSN 1337-8384 
In the second experiment the respondents were asked to evaluate the presented news texts on the previously specified parameters of "masculine" and "feminine" text generating markers. The responses given by the experiment participants suggest the following: most respondents consider that news texts of male authors are characterized by a considerable number of terms, stylistically neutral vocabulary, precise information and its generalization, citing officials. Only $15 \%$ of respondents pointed out to emotional and emotive vocabulary as a text parameter of male authors. The majority of both native and non-native speakers responded that news texts of female authors are mainly identified on the basis of such specific characteristics as the increased use of emotive and evaluative vocabulary, particularizing and detailed information, citing people hit by a calamity. The percentage of the specified parameters of "masculine" and "feminine" styles of text generating from the second experiment are presented in Tables 2, 3 .

Table 2. The percentage of the specified parameters of "masculine" style of text.

\begin{tabular}{|l|l|l|}
\hline $\begin{array}{l}\text { Parameters of "masculine" } \\
\text { style of text generating }\end{array}$ & $\begin{array}{l}\text { Native } \\
\text { English } \\
\text { speakers (\%) }\end{array}$ & Non-native English speakers (\%) \\
\hline $\begin{array}{l}\text { Emotive, evaluative, } \\
\text { figurative vocabulary }\end{array}$ & 15 & 20 \\
\hline Terminology neutral & 79 & 82 \\
\hline $\begin{array}{l}\text { Stylistically } \\
\text { vocabulary }\end{array}$ & 73 & 88 \\
\hline Generalizing information & 12 & 21 \\
\hline $\begin{array}{l}\text { Particularizing } \\
\text { information }\end{array}$ & 63 & 52 \\
\hline Precision information & 82 & 76 \\
\hline Citing officials & &
\end{tabular}

Table 3. The percentage of the specified parameters of "feminine" style of text.

\begin{tabular}{|l|l|l|}
\hline $\begin{array}{l}\text { Parameters of "feminine" } \\
\text { style of text generating }\end{array}$ & $\begin{array}{l}\text { Native English } \\
\text { speakers }(\%)\end{array}$ & $\begin{array}{l}\text { Non-native English speakers } \\
(\%)\end{array}$ \\
\hline $\begin{array}{l}\text { Emotive, evaluative, } \\
\text { figurative vocabulary }\end{array}$ & 85 & 80 \\
\hline Terminology neutral & 37 & 18 \\
\hline $\begin{array}{l}\text { Stylistically } \\
\text { vocabulary }\end{array}$ & 29 \\
\hline $\begin{array}{l}\text { Generalizing information } \\
\text { Particularizing information }\end{array}$ & 27 & 12 \\
\hline Precision information py a & 37 & 79 \\
\hline $\begin{array}{l}\text { Citing people hit by a } \\
\text { calamity. }\end{array}$ & 69 & 38 \\
\hline
\end{tabular}

\section{Mass Media Discourse Parameters}

\subsection{Gender specificity of mass media discourse deployment}


The research perspective taken in the current paper is based on the following assumptions:

- news texts possess certain genre peculiarities pertaining to identification of male and female styles of mass media discourse deployment;

- they are the reflection of a specific author's perception and description of an event expressed at the contents, structural and stylistic levels of the language system;

- $\quad$ empirical research of mass media discourse deployment enables to verify the validity of news text gender parameters.

The pragmatic function of a news text as the information genre of mass media discourse in general is informing a reader about current events (Kim , 2001), thus, information contained in the news determines the structure and contents of the text. Publications of this genre include not only a factual summary of an event, but also elements of evaluation, prediction, comments on possible consequences of this or that event (Tertychny, 2000).

The thematic focus of a news text, as the results of our sociolinguistic experiment suggest, is the crucial parameter of gender markedness of a particular news text. It is determined by social stereotypes about the spheres of informational "influence" traditionally assigned by society to fe/male journalists. The analysis of thematic preferences of fe/male authors in the British press has enabled to specify male topics (sport, politics, economics, business, science); and female topics (fashion, social security, health, education, culture).

Table 4. Thematic preference of fe/male authors in the British press

\begin{tabular}{|l|l|l|l|l|l|}
\hline topic & $\begin{array}{l}\text { male } \\
\text { authors }(\%)\end{array}$ & $\begin{array}{l}\text { female } \\
\text { authors }(\%)\end{array}$ & topic & $\begin{array}{l}\text { female } \\
\text { authors }(\%)\end{array}$ & $\begin{array}{l}\text { male } \\
\text { authors }(\%)\end{array}$ \\
\hline sport & 86,8 & 13,2 & fashion & 78,9 & 21,1 \\
\hline politics & 72,1 & 27,9 & $\begin{array}{l}\text { social } \\
\text { security }\end{array}$ & 74,2 & 25,8 \\
\hline economics & 68,5 & 31,5 & health & 72,5 & 27,5 \\
\hline business & 64 & 36 & education & 67,5 & 32,5 \\
\hline science & 63 & 37 & culture & 61,5 & 38,5 \\
\hline
\end{tabular}

\subsection{Matrix for identifying gender of a news text author}

The sociolinguistic experiment has confirmed the validity of the specified parameters of gender-marked news texts and the ability of native English speakers to identify the gender of an author even in gender neutral news texts. It has enabled us to develop a matrix for identifying the gender of a news text author (Table 5). 


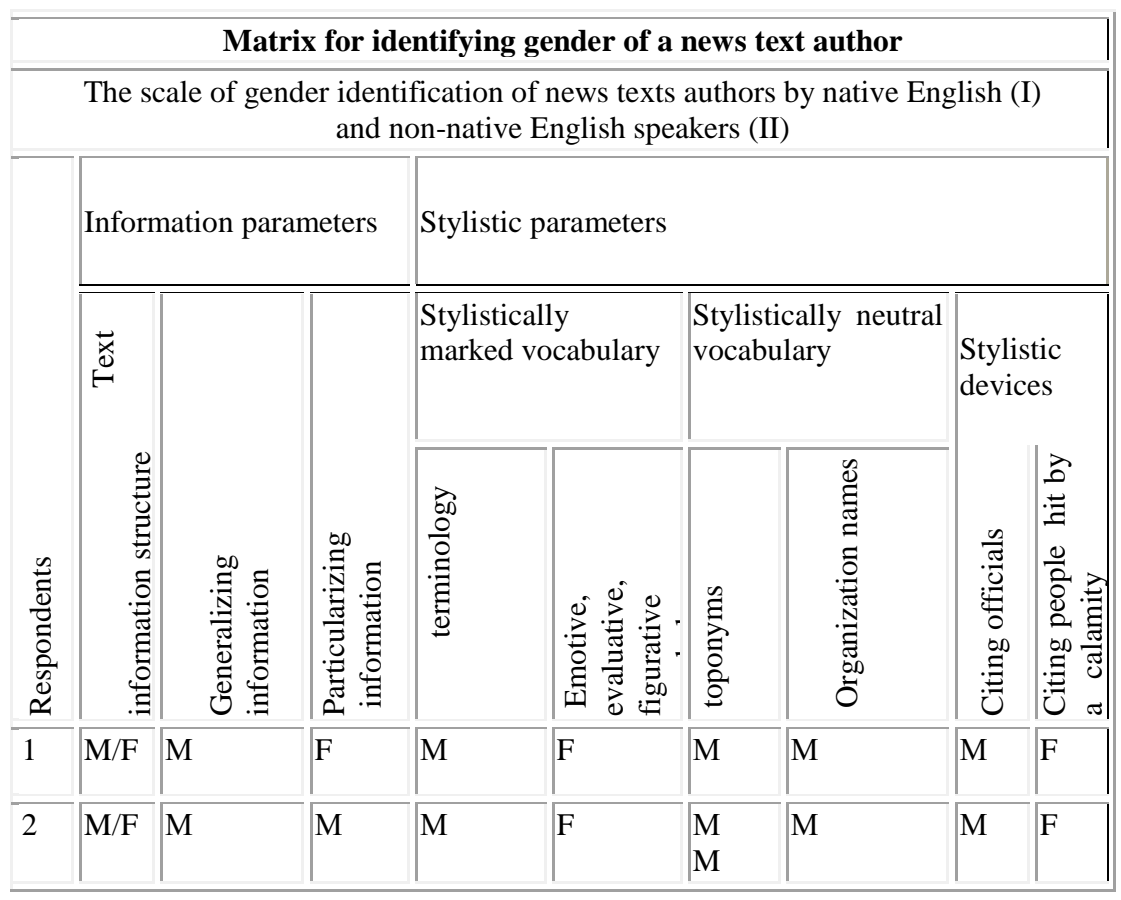

It has already been mentioned that at the first stage of the experiment the respondents have almost accurately defined a text author's gender on the basis of its thematic focus. The second stage of the experiment was aimed at verifying the validity of the remaining parameters of identifying gender of a text author. We have selected news texts of gender-neutral topics, informing about different types of calamities (hurricanes, earthquakes, landslides, typhoons, tsunamis), equally covered by male and female authors but in different manner (authors' sex was checked in Internet sources). The analysis of gender neutral news texts has revealed that the differences are found in variability of contents aspects of a covered event, structuring of information blocks, linguistic and stylistic means of an event description.

The specificity of a news text contents as presented by male authors is in prevailing coverage of political, legal, economic and scientific problems associated with calamities in a pandemic way; "male" texts are full of political (state of emergency, anarchy, foreign donors, anti-corruption campaigners, etc.), economic, legal and scientific terms (frozen funds, to issue contracts, contractors, subcontractors, fraud, criminal proceeding, looting, lawlessness, inquest, hearing, coroner, to preside, ground-penetrating radar, electromagnetic waves, underground structures, etc). Female authors mainly cover personal or social problems of those who have suffered from calamities, highlighting it in the titles of news texts: "Katrina is sent by God to punish New Orleans gays"; "New Orleans may lose $80 \%$ of its black people, says Katrina stud"; "This is turning into the ethnic cleansing of New Orleans"; "Asian earthquake victims are missing out on school"; "Many motorists were unable to claim for tornado damage" etc.). Along with social aspects of an event, female journalists often cover economic, legal and political consequences of a calamity as seen within a particular social group or person, in this way levelling masculine and feminine differences: "Brown calls for aid 'shock' fund, Millions pledged for tsunami go 
unpaid"; "Computer models predict direction of molten lava flows", "Laughing stock of Katrina makes disaster his business", etc.

Thus, the contents aspect of an event coverage is determined by psychological peculiarities of reality perception by men and women: a man takes and assesses a situation as a whole, and is more interested in the broader impact of an event without going into details, that is why male authors extrapolate the problems of a country into the global community (Shejnov, 2002): "China becomes the world's third largest donor of food", "Hundreds dead or missing in North Korea", "Indonesia faces new mega-tsunami, Quake devastates Java" etc. Women are more likely to focus their attention on details and thoroughly analyze a local event: Britons get fast-track visas, Birmingham University houses tornado victims, Up to 150 Britons yet to be found, Lloyd's fears Rita may bring $\$ 60$ bn. stress test to life etc. The distinctive feature of female information presentation is its concreteness, anthropocentrism and social orientation: emphasizing the aftermaths and consequences of a calamity for a particular individual or social group. The specific character of psychological reality perception by men and women is determined by the peculiarities of gender identity in children: girls' gender identity is accompanied by unbreakable bonds and identifying themselves with their mothers, while being fully aware of human relationships significance, whereas boys' gender identity is related to opposing themselves to their mothers and isolation, underlying their independence (Gilligan, 1982).

The research undertaken has shown that female authors tend to particularize information while men are bound to generalize. Thus, nominating participants of an event male authors often use collective nouns and substantivized adjectives: people, the survivors, victims, the affected, the injured, female authors name concrete personal and social parameters of event participants:

- biological parameters and physical/mental states (The poorest and most vulnerable members of the community, such as the elderly and the sick, were worst hit... etc.);

- race ( ... poor, mostly black citizens of New Orleans begging for food ..., ... worst damaged by the storm were African American..., ... the first British survivors began arriving home... etc.).

- personality traits and appearance (... pleaded the man in the yellow jacket and blue trousers etc.);

- social and professional status (Alice`s mother, who worked as a charity arts officer..., ...her husband, Michael, a shipbroker... etc.).

Gender specificity of "informativity" category by linguistic means is exemplified in structuring information blocks of news texts created by male and female authors. Our research results suggest that male authors mainly stick to truncated model of a news text, elaborated by T. Van Dijk: Title - Introduction - Main Event - Comments Background - Response - Consequences - Circumstances, i.e. putting information blocks in strict logical order. Female authors' texts often lack such blocks as Background, Circumstances. Women tend to vary the mentioned information blocks or merge them. The shift of information blocks in a "feminine" text is explained by their greater informativity significance for a female author and implementation of her emotional impact on a reader, appealing to his/her empathy and compassion (Dijk, 1989).

Emotional involvement of a female author in a covered situation explains information reiteration about various aftermaths of a calamity, its visualization by citing witnesses of a particular event describing in detail their feelings, experiences, etc. Male authors largely rely on an opinion of officials, stating dates, times, names and figures, i.e. precision information. Prevailing of factual information is also substantiated by the use of toponyms (...houses in the town of Kalemie, on the shores of Lake Tanganyika 
in eastern Congo, The hurricane, which left 32 people in Haiti and Cuba dead, arrived in Alabama and northwestern Florida..., Beaches in Sri Lanka and the Indian state of Tamil Nadu were strewn with bodies» etc.); names of international and foreign organizations, communities, institutions (British International Rescue Dogs, the Department for International Development, the Disaster and Emergency Committee, the Pacific Tsunami Warning Center, the UN children's agency UNICEF, the Tsunami Evaluation Coalition, the Pakistani High Commission, the Foreign Office et.), thus increasing a reader's confidence of the presented information.

\subsection{Expressivity in news texts}

Another important aspect of gender specificity studies of news texts is the category of expressivity emphasizing emotional, evaluative and figurative components of a news text. "Masculine" emotions are verbalized by emotive vocabulary describing calamities and their political and economic consequences for a particular nation (ferocious super-typhoon, nightmarish earthquake, horrendous damage, terrifying economic consequences, etc.), while "feminine" ones are in women's inborn empathy, attention to details, ability to decode non-verbal signals (Henley, 1977; Shejnov, 2002) to determine mental and emotional states (clutch $\mathrm{v}=$ hold something or someone tightly, especially because you are frightened, in pain; crumple $\mathrm{v}=$ be distorted in agony; distress $\mathrm{v}=$ make someone feel very upset or worried; bang $\mathrm{v}=$ make a sudden very loud noise nervously, sob v = cry noisily, taking in deep breaths; rack $\mathrm{v}=$ experience physical or mental pain, tremble $\mathrm{v}=$ shake gently with fear; be exhausted = be extremely tired; scream $\mathrm{v}=$ cry loudly because of strong emotions such as fear, anger etc. - LDCE; suffer $\mathrm{v}=$ feel pain or sadness; frighten $\mathrm{v}=$ make someone feel fear; scare $\mathrm{v}=$ feel worried etc. - CALD).

Expressivity of a news text is also reflected in positive or negative evaluation of different aspects of an event (its context, participants and their actions, etc). Female authors normally express their vision of an event by using:

- adjective superlative degree suffix (the costliest insured natural disaster in the world, the strongest hurricane, one of the deadliest storm seasons in the southern United States, etc.);

- emotive adjectives ( awesome hurricane, devastating earthquake, catastrophic flood etc.).

Creating a particular image by comparing two things on the basis of some common feature also contributes to expressivity. In a news text it can be achieved by such stylistic devices as personification, metaphor and simile. Male authors often assign some features found in animate objects to calamities personifying them: The quake convulsion buckled the earth, chewed up buses and levelled practically every building in sight; African earthquake buries children in homes; ... the town has been eaten alive et. Gender peculiarities of creating a particular image by female authors is explained by some features of their associative and metaphorical reasoning (Goroshko, 2001), women mainly compare inanimate objects and phenomena to human-like creatures while men - to artifacts. In the following example a city destroyed by an earthquake with school concrete walls crashing children are compared to tombstones (...the concrete slab roofs of schools across Kashmir and North West Frontier province fell like tombstones, crushing children at their desks),the city where it happened - to a place cursed by God (It looks like God has cursed this place), the ruins of villages - to archeological excavations (The remains are just visible in the snow, like the site of an archaeological dig. Female authors associate a flooded city with a sick old man abandoned to die alone (Like a sickly old patient left out to die, the coastal town...), a resort devastated by tornado is compared to a ghost (But the place, once the epitome of packaged fun, still feels much like a ghost, with windowless high-rises and empty streets). 
The stylistic analysis of news texts of the British press suggests that men possess a far higher level of linguistic creativity than women exemplified by their use of broader and more varied "arsenal" of stylistic devices: metaphors (Now it is again the valley of death), epithets (stubborn residents, harassed and intimidated girls), parallel constructions (There are no food queues, no water tankers, no tents...), antithesis (They came from all walks of life - laborers, office clerks and university lecturers bringing modest supplies of medicine, food but an abundant promise of help), gradation (Memories of that terrible morning last October - when the earth rumbled, buckled and killed more than 87,000 people...), oxymoron (But after the rain, Chinese rescuers brought well-known news), simile (It sounded like there was a jet engine in the backyard), rhetorical questions (Who cares?). Female authors mostly use only epithets, gradation, similes, anaphora.

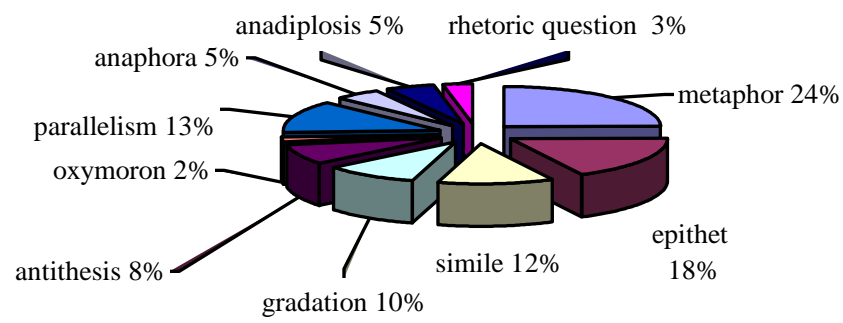

Chart 1. Stylistic devices used by male authors

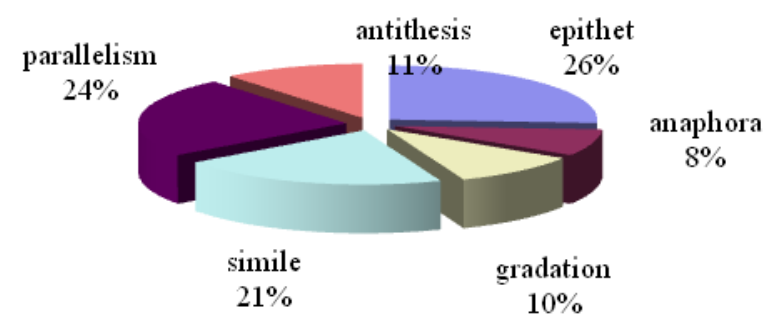

Chart 2. Stylistic devices used by female authors

The analysis of news texts has also shown that female and male authors differ in the ways they cite the witnesses of certain events. The former cite mainly female calamity witnesses emotionally describing their physical and mental states, the caused damage, their sorrow and grief, in this way creating the so called effect of presence and appealing to readers' feelings. Poly Curtis cites a female citizen of Saudi Arabia who has just gone through a devastating tsunami to create a visual and acoustic image of the calamity having additional impact on a reader: A Saudi man, who was caught in the wave and separated from his wife and son, said: "It was horrible... We were spun 
like in a washing machine... I've never heard anything like it. It sounded like there was a jet engine in the backyard. It was just this scream.

In contrast, male authors, citing witnesses of calamities (mainly males) emphasize their courage, dedication in their struggle against a calamity, persistence in overcoming its aftermaths, i.e. masculine psychological features. So, Declan Walsh, cites a Pakistani citizen helping the neighboring villagers after the earthquake despite his serious injuries: "I felt it was my duty to come and help... Sometime I was sick and my shoulder was bleeding... They appealed for volunteers at my local mosque last night, it was my duty to save the alive ..." said Muhammad Yunis, a 40-year-old farmer carrying a farmyard hoe in his hand». Besides, male authors willingly cite officials giving rational evaluation of the caused damage, commenting on government aid, compensations for calamity victims: Pakistan's president, General Pervez Musharraf, appealed to the world for help, saying: "We seek international assistance. We have enough manpower, but we need financial support." The country needed medicine, tents, cargo helicopters and financial assistance to help survivors", he said; "China's food aid to victims of earthquakes in Indonesia and Pakistan soared by $260 \%$ compared to 2005, accounting for more than half of the rise in overall food aid donations in 2006", said the representative of WFP (World Food Program).

\section{Conclusion}

Thus, our research on gender parameters of news texts has enabled to differentiate between masculine and feminine styles of discourse deployment. They are manifested in their contents and structural specificity, ways of particularizing/generalizing information, the use of neutral/emotive vocabulary, selectivity of stylistic devices, all of which are included in the matrix of identifying gender of a news text author.

Validity of the specified gender parameters of news texts was confirmed at the second stage of the sociolinguistic experiment where respondents were asked to read 6 news texts of gender-neutral topics and identify an author's gender. Its results have verified the parameters of "masculine" and "feminine" discourse deployment of a news text. News texts have retained their gender markedness manifested in male and female peculiarities of event perception and their description of gender-neutral topics at contents, structural and stylistic levels as well as in ways of verbalizing the categories of informativity and expressivity. This might be due to sociocultural factors and psychological features assigned by a particular community to men as representatives of the masculine subculture, communication leader characterized by independent ways of reasoning, consistency, rationality, linguistic creativity, lesser emotionality unlike women who are prone to greater emotionality, empathy, cooperation and compassion. The sociolinguistic experiment analyzed above has revealed certain correlation between the degree of respondents' "sensitivity" to news text gender specificity and national, cultural stereotypes reflected at the level of language. Further studies of gender specificity of mass media discourse deployment in different linguistic cultures are of paramount importance and interest both for the development of social sciences in general and for sociolinguistics in particular.

\section{Bibliographic References}

ALEKSANDROVA, E. S. 2013 Gender analysis of English political text. In: Philological Sciences. Issues of theory and practice: Gramota, vol. 2, n. 6(24), pp. 18 21. ISSN 1997-2911 
ALEKSANDROVA, E. S. 2016. Gender-marked implementation of speech strategies and tactics in informative dialogues. In: Philological Sciences. Issues of theory and practice: Gramota, vol. 1, n. 6, pp. 67 -70. ISSN 1997-2911

ANTHHONISSEN, C. - BLOMMAERT, J. 2007. Discourse and human rights violation. Philadelphia: John Benjamins. ISBN: 9789027222350

ASTAFUROVA, T. N. 2014. Discourse features of power discourse. In: Modern problems of linguistics and language teaching: conceptions and prospects. Volgograd: Volgograd State University Press. ISSN 1998-9911

BUTLER, J. 1990. Gender Trouble. New York: Routledge. ISBN: 0203902750,

CAMERON, D. 1998. Gender, language and discourse: a review essay. In: Signs: Women in Culture and Society, pp. 945-973. ISSN: 0097-9740

COATES, J. (Ed.) 1999. Language and Gender. In A Reader. Oxford: Blackwell Publishers. ISBN: 978-1-4051-9127-2

DEJK, T.A. VAN. 1989. Language. Cognition. Communication. - Moscow: Progress. $-312 \mathrm{p}$.

ECKERT, P. - MCCONNELL-GINET, S. 2003. Language and Gender. - Cambridge. ISBN: 9781107659360

ECKERT, P. - MCCONNELL-GINET, S. 1994.Think Practically and Look Locally: Language and Gender as Community-Based Practice'. In: C. Roman, S. Juhasz and C. Miller (eds.). The Women \& Language Debate, pp. 432-460. New Brunswick, NJ: Rutgers University Press. ISBN 10: 0813520126

FISHMAN, P. 1983. Interaction: the work women do. In: Language, Gender, and Society. Thorne et al. (eds.) Rowley, Mass.: Newbury House. ISBN-13: 9780883772683

GILLIGAN, C. 1982. In a different voice: Psychological theory of women's development. Cambridge, MA: Harvard University Press. ISBN 9780674445444

GOROSHKO, E. 2001. Language consciousness (associative paradigm) ( $\mathrm{PhD}$ Dissertation Abstract) - Moscow, - $55 \mathrm{p}$.

GRISHAEVA, L.I. 2007. Peculiarities of language use and cultural identity of communicants: monography. Voronezh State University Press. - 261 p. ISBN 978-59273-1151-4

GROSHEV, I.V. 1999. Woman's Image in Advertising. In: Woman. Gender. Culture. Moscow, pp. 331-343. ISBN 5-89997-010-3.

HENLEY, N. (eds.). 1977. Language and Sex: Difference and Dominance. Newbury House, Rowley, Massachusetts. ISBN: 0883770431

ISSERS, O.S.1999. Communicative strategies and tactics of Russian speech. - Omsk: Omsk University Press. - 284 p. ISBN 978-5-382-00698-7.

KIM, M.N. 2001. Technology of creating text by journalists. - St. Petersburg: Mikhailov Press. ISBN 5-8016-0137-6

KITAJGORODSKAYA, M.V. - ROZANOVA, N.N. 2003. Modern political communication. Text. In: Modern Russian: Social and Functional differentiation. Moscow: Languages of Slavic culture. - pp. 151-239. ISBN: 5-94457-084-9

LAKOFF, R. 1973. Language and Women's Place. N.Y. ISBN 0-19-516757-0

MALTZ, D.N. - BORKER, R.A. 1982. A Cultural Approach to Male-Female Miscommunication. In: J.J. Gumperz, ed., Language and Social Identity / Cambridge. ISBN 0-521-28897-5

MCCONNELL-GINET. 1984. The Origins of Sexist Language in Discourse. In: Annals of the New York Academy of Sciences, n.433, pp. 123-135. ISSN: 1749-6632. SHEJNOV, V.P. 2002. Man and Woman. Encyclopedia of relationship. - St. Petersburg: Course - 639 p. ISBN: 985-13-0733-5 
SKRYNNIKOVA, I.V. 2010. Gender aspect of space categorization. In: Integration processes in regional communicative space. - Volgograd: Volgograd State University Press. ISBN 978-5-9669-0773-0

STERNIN, I.A. 1999. Concepts and Non-Verbal Character of Cognition. In: Philology and Culture. - Tambov: TSU. -489 p. ISBN 5-8465-0029-3

TANNEN, D. 1994. Gender and Discourse. Oxford: Oxford University Press. ISBN13: 978-0195101249

TERTYCHNY, A.A. 2001. Genres of periodicals. Tutorial. Moscow: Aspect Press. ISBN 978-5-75-67-0729-8

TOLSON, A. 2006. Media talk: Spoken Discourse on TV and radio. Edinburgh Edinburgh University Press. ISBN 074862631X

WEST, C. - ZIMMERMAN, D. H. 1983. Small insults: A study of interruptions in cross-sex conversations between unacquainted persons. In: B. Thorne, C. Kramarae, \& N. Henley (Eds.) Language, gender and society. Cambridge, MA: Newbury House. ISBN-13: 978-0883772683

ZDRAVOMYSLOVA, E.A. - TEMKINA, A.A. 2000. Introduction into Feminist Translation: text, author, discourse. In: Feminists Texts Reader. Translation. - St. Petersburg. ISBN 5-86007-252-x.

ZIMMERMAN, D. - WEST, C. 1975. Sex, Interruptions and Silences in Conversation. In: Language and Sex: Difference and Dominance. Newbury House, Rowley, MA: Newbury House. ISBN-13: 978-0883770436

Words: 4304

Characters: 29160 (16,2 standard pages)

Inna V. Skrynnikova, Associate Professor, $\mathrm{PhD}$

Institute of Philology and Intercultural Communication

Volgograd State University

Volgograd, 400062, Universitetskij prospekt, 100.

Russian Federation

i.skrynnikova@volsu.ru

Tatjana N. Astafurova

Full Professor, Doctor of Philology

Institute of Philology and Intercultural Communication

Volgograd State University

Volgograd, 400062, Universitetskij prospekt, 100.

Russian Federation

t.astafurova@volsu.ru

Associate Professor, PhD. Elena S. Aleksandrova

Institute of Philology and Intercultural Communication

Volgograd State University

Volgograd, 400062, Universitetskij prospekt, 100.

Russian Federation

e.aleksandrova@volsu.ru 